\title{
Skin Protectants Made of Curable Polymers: Effect of Application on Local Skin Temperature
}

\author{
Michael J. Walt, ${ }^{1}$ Nancy Atwood, ${ }^{1}$ Stéphanie F. Bernatchez, ${ }^{1, *}$ \\ Bruce P. Ekholm, and Robert Asmus ${ }^{2}$ \\ ${ }^{1} 3 \mathrm{M}$ Health Care Clinical Operations, St. Paul, Minnesota. \\ ${ }^{2} 3$ M Critical \& Chronic Care Solutions Division, St. Paul, Minnesota.
}

Objective: To measure the skin temperature after application of a new skin protectant intended for incontinence-associated dermatitis (IAD), compared with a commercial product with an analogous cyanoacrylate-based chemistry. Approach: Twelve healthy human volunteers received an application of the new product on one thigh and of the comparator on the other thigh. An infrared camera using ThermaCAM ${ }^{\mathrm{TM}}$ software imaged the skin and measured the temperature at the skin surface over time to characterize the thermal cure profile induced by the products on the skin.

Results: The new product led to a drop in skin surface temperature (endothermic reaction), whereas the commercial product displayed an exotherm and a slight rise in skin surface temperature.

Innovation: Cyanoacrylate-based chemistries come in various formulations, differing in the side chains and additives used. They are liquid monomers that polymerize after application, and this polymerization is accompanied by an exothermic reaction that can be perceived as an unpleasant warming sensation, especially on compromised skin. A new formulation was designed to mitigate this rise in temperature.

Conclusion: The new skin protectant may potentially be more comfortable for IAD patients, since it causes a drop in skin surface temperature instead of a rise during the curing process that follows application.

Keywords: skin protectant, cyanoacrylate, skin temperature, incontinenceassociated dermatitis

\section{INTRODUCTION}

SUPERFICIAL SKIN DAMAGE occurs in various circumstances, such as skin tears and moisture-associated skin damage (MASD). MASD includes conditions such as incontinence-associated dermatitis (IAD), intertriginous dermatitis, periwound moisture-associated dermatitis, and peristomal moisture-associated dermatitis. This topic has been reviewed by Gray et $a l .{ }^{1}$ In many circumstances, areas of breakdown are difficult to manage with dressings due to anatomic location and the presence of incontinence. Products that can be spread, sprayed, or painted on the skin have been developed to manage these conditions.

A new skin protectant with improved adhesion to denuded skin,

(c) Michael J. Walt, et al., 2017; Published by Mary Ann Liebert, Inc. This Open Access article is distributed under the terms of the Creative Commons Attribution Noncommercial License (http:// creativecommons.org/licenses/by-nc/4.0/) which permits any noncommercial use, distribution, and reproduction in any medium, provided the original author(s) and the source are credited.

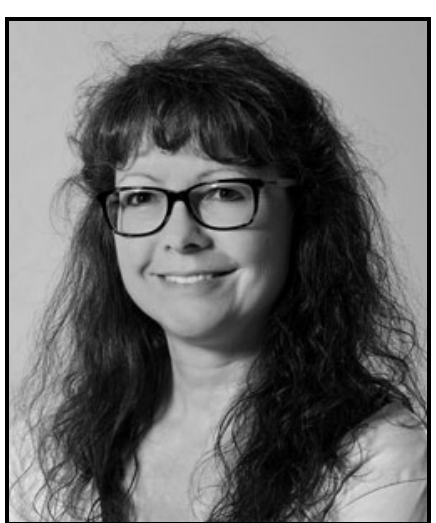

Stéphanie F. Bernatchez, PhD

Submitted for publication September 2, 2016. Accepted in revised form October 5, 2016.

*Correspondence: $3 \mathrm{M}$ Health Care Clinical Operations, 3M Center Building 270-3A-04, St. Paul, MN 55144-1000

(e-mail: sfbernatchez@mmm.com). 
improved barrier properties, and improved durability has been designed to protect skin with denudement, such as seen with IAD. The investigational formulation is based on customized acrylic polymers combined with 2-octyl cyanoacrylate to form a film structure curing after application. Curing reactions can be accompanied by changes in temperature, and the curing of cyanoacrylatebased chemistries occurs through an exothermic polymerization reaction. ${ }^{2}$ Heat is, therefore, released in the process, possibly leading to a burning sensation. Patients with IAD frequently report high levels of pain, particularly during cleansing after an incontinence episode and during the application of the product intended to protect the skin. Temperature and pain are generally considered to be separate sensory systems that are served by different receptors and afferent fibers within the skin. ${ }^{3}$ It is reasonable to expect that these sensations may be more intense in denuded skin. Cooling or heating the skin can cause stinging, pricking, or burning, and sensory thresholds are recognized as being highly individual and subjective. For skin temperature measurements, the proposed clinically significant mean skin temperature difference is $\pm 0.5^{\circ} \mathrm{C}$ and the limits of agreements between different measuring methods are $\pm 1.0^{\circ} \mathrm{C}$. ${ }^{4}$

The objective of this study is to investigate the effect of the application of curing skin protectant formulations on the local skin temperature of healthy subjects in a laboratory setting.

\section{CLINICAL PROBLEM ADDRESSED}

Cyanoacrylate-based products can be used in the management of superficial skin damage. A possible limitation of this chemistry is the burning sensation that can be experienced by patients due to the exothermic polymerization reaction. ${ }^{2}$ This article describes a new skin protectant formulated to mitigate this effect and to eliminate the rise in skin temperature after application.

\section{SUBJECTS AND METHODS}

Twelve healthy volunteers were recruited to participate in a study protocol approved by our Institutional Review Board (IRB). The goal was to measure the skin temperature after applying a new skin protectant compared with a commercial product with an analogous cyanoacrylate-based curing chemistry.

The investigational formulation tested is a solution based on a patented acrylate chemistry, which forms a durable, transparent elastomeric barrier on application to skin. This film is breathable and capable of preventing irritants from reaching the skin surface (data on file). A customized acrylic polymer, combined with 2-octyl cyanoacrylate, creates the film structure, as illustrated in Fig. 1. The film formers are delivered from a well-tolerated solvent. Testing done before applying the product to humans included cytotoxicity, irritation, sensitization, genotoxicity, and systemic toxicity based on the criteria of expected use ( $>30$ days in contact with a breached skin barrier) and guidance covering the biological evaluation of medical devices outlined in EN ISO 10993-1:2009. The results supported the conclusion that the product is safe for its intended use. Animal models were also used to test this product. ${ }^{5}$

Volunteers were asked to not use skin creams or lotions on the test sites for $24 \mathrm{~h}$ before the study and to not exercise before testing on the day of the study. A skin marking pen was used to mark a $3 \times 3$ inch area on the mid-anterior part of both thighs for each subject. The hair was clipped if necessary. Areas were marked on each corner with an aluminum dot (for camera positioning). Subjects took a seated position and were allowed to acclimate to the room temperature for $30 \mathrm{~min}$, and a baseline
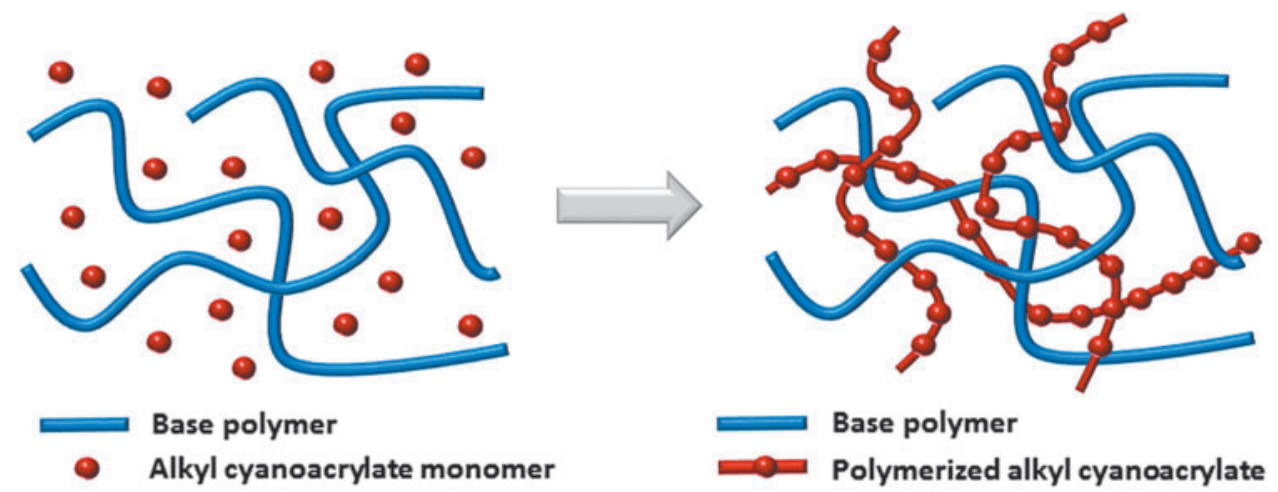

Figure 1. Cartoon representation of the interpenetrating molecular network of the new skin protectant both before and after curing. 


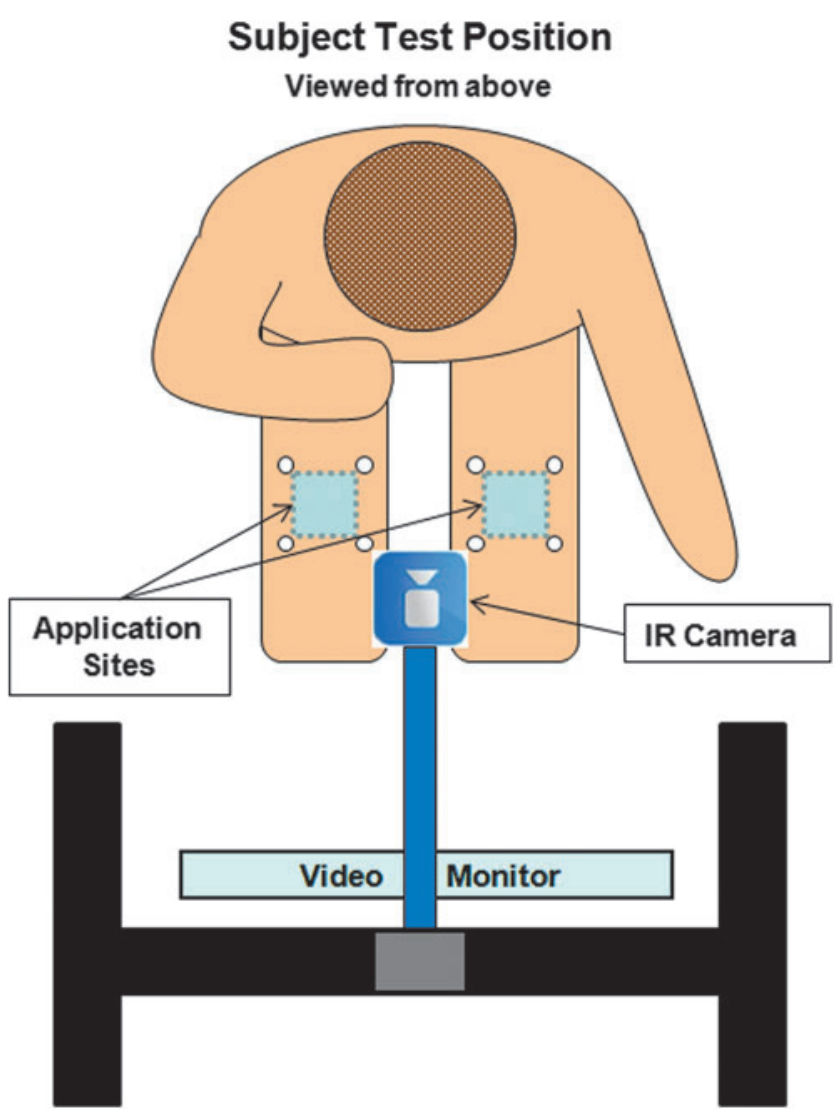

Figure 2. Subject test position.

skin temperature measurement was obtained by using a thermographic camera system (FLIR SC660 infrared camera with ThermaCAM ${ }^{\mathrm{TM}}$ Researcher Pro software v2.9, United Kingdom). The set-up is illustrated in Fig. 2. The products (new investigative skin protectant and Marathon ${ }^{\circledR}$ Liquid Skin Protectant; Medline Industries, Mundelein, IL) were applied simultaneously by two investigators, one on each thigh of each subject according to a randomization schedule. Postapplication, the skin temperature was measured every $15 \mathrm{~s}$ for $6 \mathrm{~min}$, for a total of 25 pictures per subject.

The first image in each sequence was the "baseline" image taken after subject acclimatization for $30 \mathrm{~min}$ and before product application. The second image in each sequence was taken $15 \mathrm{~s}$ after application of both products was complete. The last image was taken $6 \mathrm{~min}$ ( $360 \mathrm{~s}$ ) after application of both products was complete. The reference image for subtraction was the baseline image for each subject. This baseline was subtracted from each subsequent image.

\section{Statistical Methods}

Thermal data were analyzed by subtraction of the baseline skin temperature from the post-test

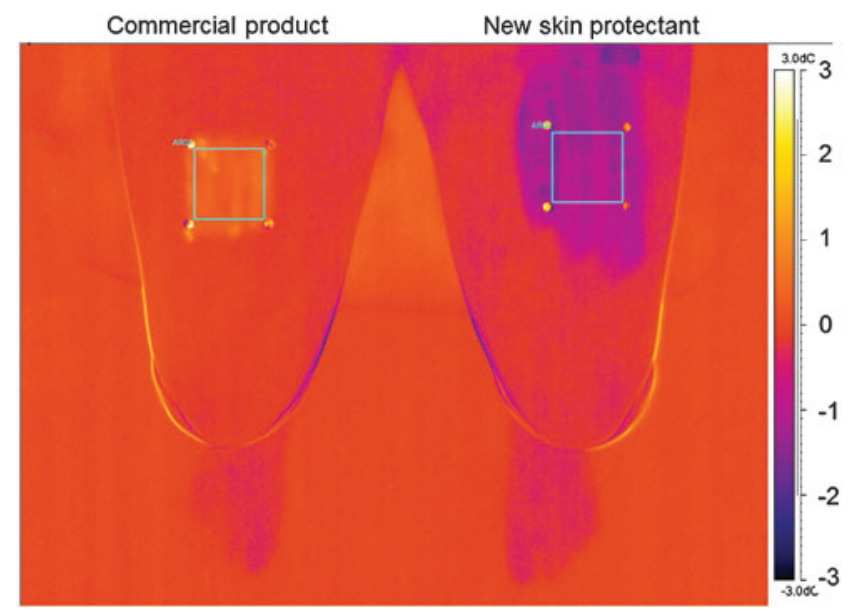

Figure 3. Representative image from the thermal camera with temperature scale on the right hand side. The temperature scale expresses the difference from baseline (set at $0^{\circ} \mathrm{C}$ ). This image shows the $15 \mathrm{~s}$ time point (15 $\mathrm{s}$ after product application). The left side of the image (right thigh on this subject) received the commercial product, and the area of application displays a rise in temperature (toward the yellow end of the temperature scale); the right side of the image (left thigh on this subject) received the new skin protectant, and the area of application displays a decrease in temperature (toward the purple end of the temperature scale).

condition temperatures (every $15 \mathrm{~s}$ for $6 \mathrm{~min}$ ) on stored digital images. The data were compared at each time point by using a mixed-model analysis of variance with subject as a random factor and protectant as a fixed factor. A $p$-value of less than 0.05 was considered significant. This same model was used to test whether the change at each time for each protectant was statistically significant from zero.

The peak change was calculated for each subject and protectant. If the largest change was in the negative direction, that was used. If the largest change was in the positive direction, that was used. The peak change was tested with the same statistical model.

\section{RESULTS}

In our study, the new product led to a drop in skin surface temperature (endothermic reaction) per camera imaging, whereas the commercial product displayed an exotherm and a slight rise in skin temperature. Figure 3 provides a representative example of an image from the thermal camera.

Figure 4 displays the mean temperature measured every $15 \mathrm{~s}$ for $6 \mathrm{~min}$ for the 2 products tested ( $n=12$ for each product).

The statistical analysis showed a significant $(p<0.001)$ difference between the treatment groups at each time point (Fig. 4). For the commercial skin protectant, the temperature change 


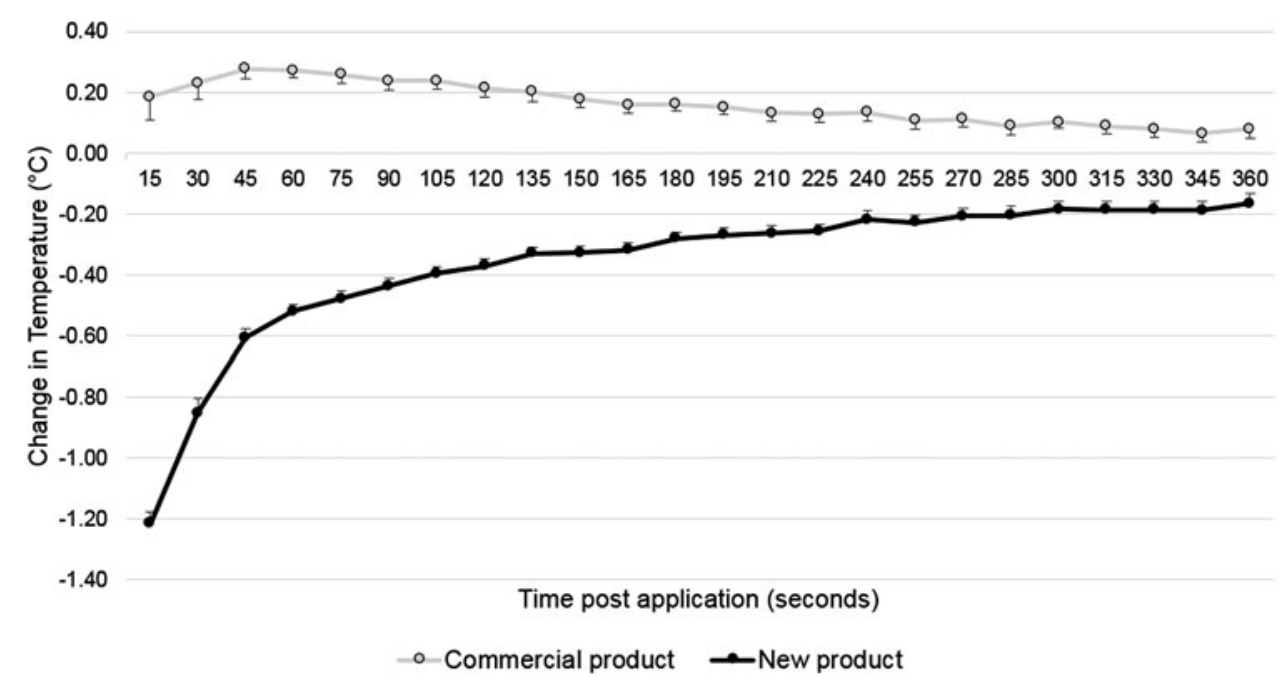

Figure 4. Mean change in temperature $\left({ }^{\circ} \mathrm{C}\right)$ for 12 subjects (bars represent the standard error of the mean). The difference between protectants was significant $(p<0.001)$ at all time points.

was significant (different from $0^{\circ} \mathrm{C}$, with a rise in temperature) at all time points from 30 to $270 \mathrm{~s}$, and for the new skin protectant, the temperature change was significant (different from $0^{\circ} \mathrm{C}$, with a decrease in temperature) at all time points, that is, $15-360 \mathrm{~s}$.

In each treatment group, the biggest change in temperature (peak) was identified for each subject and the mean of these values was calculated. For the commercial skin protectant, the mean peak increase was $+0.3^{\circ} \mathrm{C}$, and for the new skin protectant, the mean peak decrease was $-1.2^{\circ} \mathrm{C}$. The difference in the peak changes was statistically significant $(p<0.001)$ between the two protectants. The estimate of the mean difference was $1.5^{\circ} \mathrm{C}$, with a standard error of 0.054 .

\section{DISCUSSION}

This study looked at the thermal curing profile of a new skin protectant and a commercial product comparator after application to the skin of 12 healthy volunteers (one product on each thigh). There was a statistically significant difference in temperature at the skin surface between the two protectants. The difference was consistent across all 12 subjects, with results showing a decrease in temperature for the new product and an increase in temperature for the comparator. These temperature changes were statistically different from baseline for both products.

Cyanoacrylates include methyl-2-cyanoacrylate, ethyl-2-cyanoacrylate (found in commercial glues and branded as "Super Glue" and "Krazy Glue"), n-butyl-cyanoacrylate, and 2-octyl-cyanoacrylate.
They are unique in their ability to instantly polymerize at room temperature when applied to a surface: The polymerization is triggered by the presence of trace amounts of weakly basic or nucleophilic species on the surface, including moisture. Cyanoacrylate adhesives cure rapidly on skin surfaces (within 5-60 s). ${ }^{6}$ The first generation of cyanoacrylate adhesives were based on lower alkyl (methyl) ester monomers and caused tissue toxicity. Research showed that the longer the hydrocarbon group at the $-\mathrm{R}$ position, the slower the rate of polymerization, the less heat released during polymerization, and the lower the histotoxicity. ${ }^{7}$ In addition, longer chain esters degrade much slower, allowing more efficient metabolism of the degradation products and reducing the inflammatory response. ${ }^{8} 2$-octyl-cyanoacrylate was developed to address toxicity concern and to reduce skin irritation and allergic response, improving properties for medical applications.

Cyanoacrylates were first introduced for medical use as skin tissue adhesives to approximate the edges of incisional wounds and to achieve closure by primary intention. ${ }^{9}$ In some circumstances, they can provide an alternative to sutures and staples for surgical wounds ${ }^{10}$ and for simple traumatic lacerations. ${ }^{11}$ Another use for cyanoacrylates has been as a preoperative skin care strategy, applying them on top of the surgical skin prep to reduce surgical site infections (SSIs) by immobilizing any bacteria left on the skin after prepping and to prevent growth. A Cochrane review published on this topic concludes that the results show a significant difference, but it cautiously states that more research is needed. ${ }^{12}$ Dohmen has also reviewed 
the literature on this and concluded that this approach is an attractive option to reduce SSIs. ${ }^{13}$ In a similar thought process, Grimaldi et al. shared their experience of using octyl-2-cyanoacrylate to cover the suture after surgical incision closure and reported a decrease in the incidence of wound infection and wound dehiscence in a group of 900 patients over 8 years. ${ }^{14}$ The literature has described concerns in using such adhesives in the actual incision, reporting that they can delay healing by acting as a barrier between the growing edges of the incision. ${ }^{2,15,16}$ However, this may depend on the formulation, because others have reported an enhancement of the healing process in a partial-thickness wound animal model. ${ }^{17}$ The current study highlights a different application for this chemistry, consisting of a skin protectant to manage superficial skin lesions or to protect skin exposed to irritants. ${ }^{18}$

The new skin protectant presented here is delivered in a nonstinging solvent and as this solvent evaporates, the heat of volatilization causes a cooling effect, compensating for the heat released during polymerization. This composition also contains a smaller percentage of reactive chemistry than the comparator product. Comparatively, the commercial product has no solvent and contains $100 \%$ reactive monomer, leading to a greater exothermic reaction on curing. The new skin protectant may potentially be more comfortable for patients, since it does not add any heat to the skin during the curing process that follows application. An additional benefit provided by the nonstinging solvent is that it prevents the cyanoacrylate from bonding tissues together, which is a critical concern when dealing with skin folds such as the gluteal cleft where such a product is used to manage IAD.

This study has some limitations. The measurements were taken on a small number of healthy volunteers, and the skin was not damaged. However, the conditions were well controlled and the results were remarkably consistent and reproducible. This formulation has been recently tested in a clinical setting (manuscript accepted for publication) on 16 patients suffering from IAD and showed promise for this indication. A larger scale study is underway.

\section{INNOVATION}

Film-forming tissue adhesives based on cyanoacrylate chemistries have been available since the 1950s. The first FDA-approved product for human use was Dermabond ${ }^{\circledR}$ (1998), cleared to approximate surgical wound edges. Variations in chemistries have led to different formulations and additional uses. The commonality between these cyanoacrylate-based products is their exothermic polymerization. The heat released may cause the patient to experience a burning sensation. ${ }^{2}$ This could be exacerbated in denuded skin such as is often seen with severe IAD. We present here a new formulation designed to mitigate this rise in temperature; the new skin protectant may potentially be more comfortable for patients by causing a drop in skin surface temperature instead of a rise during the curing process after application.

\section{ACKNOWLEDGMENTS AND FUNDING SOURCES}

This work was done in the laboratories of $3 \mathrm{M}$.

\section{AUTHOR DISCLOSURE AND GHOSTWRITING}

M.W., N.A., S.F.B., B.P.E., and R.A. are employees of 3M. All authors contributed to writing this article, and no ghostwriters were used to write this article.

\section{ABOUT THE AUTHORS}

Michael J. Walt received a BS in Mechanical Engineering (Biomedical) from the University of Minnesota. At 3M since 1979, he spent 18 years in mechanical testing and development of orthopedic implants. He served on the ASTM Committee F4, Medical and Surgical Devices and Materials, helping develop test standards. In 1997, he transitioned to clinical research. He has used infrared thermography to determine human skin temperature changes when exposed to electrosurgical radiofrequency (RF) current. Nancy Atwood received her BA from the University of Minnesota, and she currently works at $3 \mathrm{M}$ in clinical research. Stéphanie F. Bernatchez received her PhD in 
Interdisciplinary Sciences from the University of Geneva, Switzerland. She has worked at $3 \mathrm{M}$ in research and development for advanced wound care for 20 years. Bruce P. Ekholm received his MS in Statistics from the University of Minnesota and works at 3M. Robert Asmus received his BS with a double major in Chemistry and Physics, North Dakota State University, followed by an MS in Polymers \& Coatings at North Dakota State University. He has worked at $3 \mathrm{M}$ in product development on Medical and Surgical products for more than 30 years.

\section{REFERENCES}

1. Gray M, Black JM, Baharestani MM, et al. Moisture-associated skin damage: overview and pathophysiology. J Wound Ostomy Continence Nurs 2011;38:233-241.

2. Wackett A, Singer AJ. The role of topical skin adhesives in wound repair. Emerg Med J 2009: $31-35$

3. Green BG, Akirav C. Threshold and rate sensitivity of low-threshold thermal nociception. Eur $J$ Neurosci 2010;31:1637-1645.

4. Bach AJ, Stewart IB, Minett GM, Costello JT. Does the technique employed for skin temperature assessment alter outcomes? A systematic review. Physiol Meas 2015;36:R27-R51.

5. Been RA, Bernatchez SF, Conrad-Vlasak DM, Asmus RA, Ekholm BP, Parks PJ. In vivo methods to evaluate a new skin protectant for loss of skin integrity. Wound Repair Regen 2016;24:851-859.

6. Burns B. Polycyanoacrylates. In: Encyclopedia of Polymer Science and Technology. John Wiley \& Sons, 2016:1-27. http://onlinelibrary.wiley.com/ doi/10.1002/0471440264.pst256.pub2/abstract; jsessionid=D851C72B9A16B85582D64CD42DEAC CE3.f02t01 (last accessed Nov. 1, 2016).
7. Petrie EM. Cyanoacrylate adhesives in surgical applications. Rev Adhes Adhes 2014;2:253-310.

8. Toriumi DM. Histotoxicity of cyanoacrylate tissue adhesives: a comparative study. Arch Otolaryngol Head Neck Surg 1990;116:546-550.

9. Fischl RA. An adhesive for primary closure of skin incisions. A preliminary report. Plast Reconstr Surg Transplant Bull 1962;30:607-610.

10. Armitage J, Lockwood S. Skin incisions and wound closure. Surgery (Oxford) 2011;29:496-501.

11. Beam JW. Tissue adhesives for simple traumatic lacerations. J Athl Train 2008;43:222-224.

12. Lipp A, Phillips C, Harris P, Dowie I. Cyanoacrylate microbial sealants for skin preparation prior to surgery (Review). Cochrane Database syst Rev 2013;CD008062.

13. Dohmen PM. Impact of antimicrobial skin sealants on surgical site infections. Surg Infect (Larchmt) 2014:15:368-371.

14. Grimaldi L, Cuomo R, Brandi C, Botteri G, Nisi G, D'Aniello C. Octyl-2-cyanoacrylate adhesive for skin closure: eight years experience. In Vivo 2015; 29:145-148.
15. Donkerwolcke M, Burny F, Muster D. Tissue and bone adhesives: historical aspects. Biomaterials 1998:19:1461-1466.

16. Singer AJ, Berruti L, McClain SA. Comparative trial of octyl-cyanoacrylate and silver sulfadiazine for the treatment of full-thickness skin wounds. Wound Repair Regen 1999;7:356-361.

17. Davis SC, Eaglstein WH, Cazzaniga AL, Mertz PM An octyl-2-cyanoacrylate fromulation speeds healing of partial-thickness wounds. Dermatol Surg 2001;27:783-788.

18. Woo KY. Health economic benefits of cyanoacrylate skin protectants in the management of superficial skin lesions. Int Wound J 2014;11: 431-437.

\footnotetext{
Abbreviations and Acronyms

$I A D=$ incontinence-associated dermatitis

$\mathrm{IRB}=$ Institutional review board

MASD $=$ moisture-associated skin damage

SSI = surgical site infection
} 